\title{
STRUCTURAL PECULIARITIES OF BIGRAM-COLLOCATIONS IN LEGAL ENGLISH
}

\author{
Ol'ga M. Litvishko \\ Pyatigorsk State University, Pyatigorsk, Russia
}

\begin{abstract}
The article describes the results of research on detecting structural peculiarities of thematicallystipulated two-component set expression in legal English texts. The material under study included texts of conventions of International Labour Organization. Special attention is paid to thematic bigrams-collocations and the systematic character of their usage. Two types of bigrams are identified in the conventions: contact and distant ones. Structural peculiarities are discovered by calculating their grammatical references to notional and functional classes of words. The bigramic character is presented in the following models of combinability: notional with another notional word, notional with a function word, function with a notional word. Some ways of translating bigram-collocations into Russian are also mentioned. The potential of statistical analysis is considered as a mean to find the most frequent collocations; having analyzed one text of convention (the fragment is included into the article) the author presented a database of 200 bigram-collocations. The results of this research could be used in automatic text processing and text generating programs in the sphere of law, international employment and labour law including; more than that, they might encourage further research of structural-and-semantic features of bigramscollocations according to the type of semantic relations between their elements, and define the most often used models of bigrams in the texts used in the sphere of international law, including terminological bigrams as units of legal terminology system.

Key words: bigram, collocation, contextual combinatorial characteristics, document, international convention, labour law, legal English, English.

Citation. Litvishko O.M. Structural Peculiarities of Bigram-Collocations in Legal English. Vestnik Volgogradskogo gosudarstvennogo universiteta. Seriya 2. Yazykoznanie [Science Journal of Volgograd State University. Linguistics], 2019, vol. 18, no. 2, pp. 37-47. (in Russian). DOI: https://doi.org/10.15688/jvolsu2.2019.2.4

\section{СТРУКТУРНЫЕ ОСОБЕННОСТИ БИГРАММ-КОЛЛОКАЦИЙ В МЕЖДУНАРОДНЫХ ЮРИДИЧЕСКИХ ДОКУМЕНТАХ}

\author{
Ольга Михайловна Литвишко \\ Пятигорский государственный университет, г. Пятигорск, Россия
}

\begin{abstract}
Аннотация. В статье описаны результаты исследования по выявлению в юридических текстах на английском языке тематически обусловленных двухкомпонентных устойчивых словосочетаний с целью определения их структурных характеристик. Материалом для изучения были избраны конвенции Международной opr их использования. В конвенциях зафиксированы биграммы двух видов - контактные и дистантные. Разработана классификация биграмм-коллокаций, основанная на их репрезентации как сочетаний определенных частей речи - главных с главными, главных со служебными, служебных с главными. Охарактеризованы некоторые способы перевода биграмм-коллокаций на русский язык. На примере текста одной из конвенций продемострированы возможности статистического анализа с выявлением частотных коллокаций. Итогом проведенного анализа стала база данных биграмм-коллокаций из 200 сочетаний, фрагмент которой приво() дится в статье. Результаты работы могут быть использованы в программах автоматической обработки и
\end{abstract}


составления текстов юридической тематики, в том числе в сфере международного трудового законодательства, могут послужить основой дальнейшего анализа биграмм-коллокаций по типу семантической связи между их элементами с целью описания структурно-семантических особенностей и выявления характеризующих документ международно-правовой сферы частотных моделей биграмм, в том числе терминологических, что в целом будет способствовать развитию терминологического аппарата юрислингвистики.

Ключевые слова: биграмма, коллокация, контекстуальная сочетаемость, документ, международная конвенция, трудовое право, юридический английский язык, английский язык.

Цитирование. Литвишко О. М. Структурные особенности биграмм-коллокаций в международных юридических документах // Вестник Волгоградского государственного университета. Серия 2, Языкознание. 2019. - T. 18, № 2. - C. 37-47. - DOI: https://doi.org/10.15688/jvolsu2.2019.2.4

\section{Введение}

Изучение взаимосвязи языка и права способствовало образованию самостоятельной области знаний - правовой (или юридической) лингвистики (юрислингвистики). Ее объектом является язык государства, в том числе язык права. Язык выступает средством понимания, интерпретации и толкования всей коммуникативной деятельности в юридической сфере, включая документы международного права.

Исследование языка сферы права ведется в отечественной лингвистике с середины XX в., при этом особое внимание уделяется анализу функционально-делового стиля и выявлению особенностей его использования, вопросам генерирования нормативных текстов. Большой вклад в развитие отечественной юрислингвистики внесли А.Н. Баранов, Н.Д. Голев, А.М. Кузнецов, Л.С. Бурдин, Н.В. Солнцева и др.

В зарубежной науке основным предметом лингвоюридических исследований являются язык и стиль юридических документов, особенности, адекватность и эквивалентность их перевода, лингвистическая экспертиза, прагмалингвистическая специфика речи участников судебного процесса. Данная проблематика отражена в работах М. Култхарда, А. Джонсона, Д. Райта [Coulthard, 1994; Coulthard, Johnson, Wright, 2016], Дж. Коттерилл [Language in the Legal Process, 2002], Г. Стигал [Stygall, 2007].

В центре внимания ученых, кроме того, находятся проблемы интерпретации текста закона [Баранов, 2007; Голев, 2000; 2006; Голев, Головачева, 2005; Кузнецов, Бурдин, Солнцева, 2006], правовой коммуникации [Eckardt, 2000], ясности языка юридических документов [Язык закона, 1990; Eckardt, 2000].
Результатом этих многосторонних исследований, проводимых как отечественными, так и иностранными специалистами в области юрислингвистики, стали не только отдельные научные публикации, но и ряд учебных пособий [Callanan, Edwards, 2010; Haigh, 2015; Krois-Lindner, 2011], периодических научных изданий [Юрислингвистика; LSP and professional communication; Hermes...; The International Journal...].

Несмотря на различия подходов к изучению языка права и наличие достаточно большого количества публикаций по проблемам юрислингвистики, следует отметить, что на данный момент отсутствуют работы, в которых используются количественный и статистический методы анализа. Современные лингвоюридические исследования также не располагают классификациями языковых единиц в соответствии с задачами в этой науки. Не менее важной проблемой, требующей пристального внимания не только лингвистов, но и юристов, является терминообразование и перевод терминологической лексики с английского языка на русский, что обусловлено существенными различиями в правовых системах. Данное исследование, будучи направленным на установление и оценку закономерностей совместной встречаемости лексических единиц, их структурный анализ, способствует развитию терминологического аппарата юрислингвистики как относительно молодой отрасли.

\section{Методология и материал исследования}

Представленное междисциплинарное исследование соответствует новой методологической парадигме современной лингвистики. Оно выполнено на пересечении юридической лингвистики, лексикологии, квантитативной и корпусной лингвистики, теории и практики пере- 
вода. Это позволяет использовать ряд подходов и методик, включая контент-анализ, жанровый анализ высказывания и квантитативные методы корпусной лингвистики - диверсифицированный поиск, подсчет частотности употребления, автоматическую обработку текста, составление статистических данных.

Перспективным представляется контекстно-ориентированный подход с использованием различных статистических методик, позволяющих выделить из текстов коллокации и ранжировать их по степени неслучайности, классифицировать по структурным характеристикам. Это даст возможность не только выявить различные типы коллокаций, включая терминологические (неоднословные термины), но и расширить таким образом терминологический аппарат юрислингвистики.

Методики квантитативной и корпусной лингвистики успешно применяются в исследованиях научного, политического медиадискурса на материале русского языка [Хохлова, 2008; Ягунова, Пивоварова, 2010а; 2010б; Khokhlova, Zakharov, 2009], в работах, посвященных выявлению устойчивых словосочетаний на англоязычном материале [Evert, 2005; Khokhlova, Zakharov, 2009].

Единицами проводимого нами анализа выступают коллокации, состоящие из двух компонентов и определяемые как биграммыколлокации.

Термин «коллокация» впервые зафиксирован в «Словаре лингвистических терминов» О.С. Ахмановой в значении «лексико-фразеологически обусловленная сочетаемость слов в речи как реализация их полисемии» [Ахманова, 2007, с. 199]. Рассмотрению понятия коллокации посвящены некоторые работы (см., например: [Имплицитность в языке и речи, 1999; Иорданская, Мельчук, 2007]). Современное использование термина «коллокация» в корпусной лингвистике отражает его понимание как статистически устойчивого словосочетания (фразеологического или свободного).

Термин «биграмма» (пара символов) впервые был использован в шифре Плейфера в ручной симметричной технике шифрования государственных документов в середине XIX в. в Великобритании. В лингвистике данным термином принято обозначать пары символов, букв, слов [Collins, 1996]. Биграмма-коллока- ция - это неслучайное сочетание двух лексических единиц, связанных семантическими отношениями и употребляющихся в одном фразовом контексте.

В ходе исследования были проанализированы тексты семи основных конвенций Международной организации труда (МOT): Abolition of Forced Labour Convention, Convention Concerning Freedom of Association and Protection of the Right to Organize, Discrimination (Employment and Occupation) Convention, Equal Remuneration Convention, Forced Labour Convention, Minimum Age Convention, Right to Organize and Collective Bargaining Convention (Labour Standards). Общий статистический анализ текстового корпуса конвенций (количество слов - 14 609) с помощью интернет-сервиса Voyant Tools дал следующие результаты:

1) среднее количество слов в предложении $-42,7$;

2) 20 самых частых слов: convention (337); shall (261); article (224); labour (194); international (132); general (97); member (83); organization (79); members (73); force (72); provisions (68); age (67); work (66); director (64); office (59); minimum (56); forced (55); workers (54); compulsory (52); employment (52) (см. рис. 1, 2).

Представленные на рисунках слова часто встречаются в составе разнородных двухкомпонентных словосочетаний - биграмм. Анализ частотности употребления биграмм-коллокаций в текстах конвенций MOT с помощью статистических средств редактора MSWord и интернет-сервиса Voyant Tools направлен на выделение тематически обусловленных биграмм-коллокаций, разработку их классификации на основе структурных характеристик.

\section{Результаты и обсуждение}

Результаты анализа могут содержать определенные погрешности ввиду использования неавтоматических способов разметки рассматриваемых текстов. Однако такая погрешность варьируется в диапазоне $1-5 \%$, что не следует считать фактором искажения полученных результатов. (Применение автоматических методов разметки текстов внесет уточнения в результаты, что может стать следующим этапом работы). 


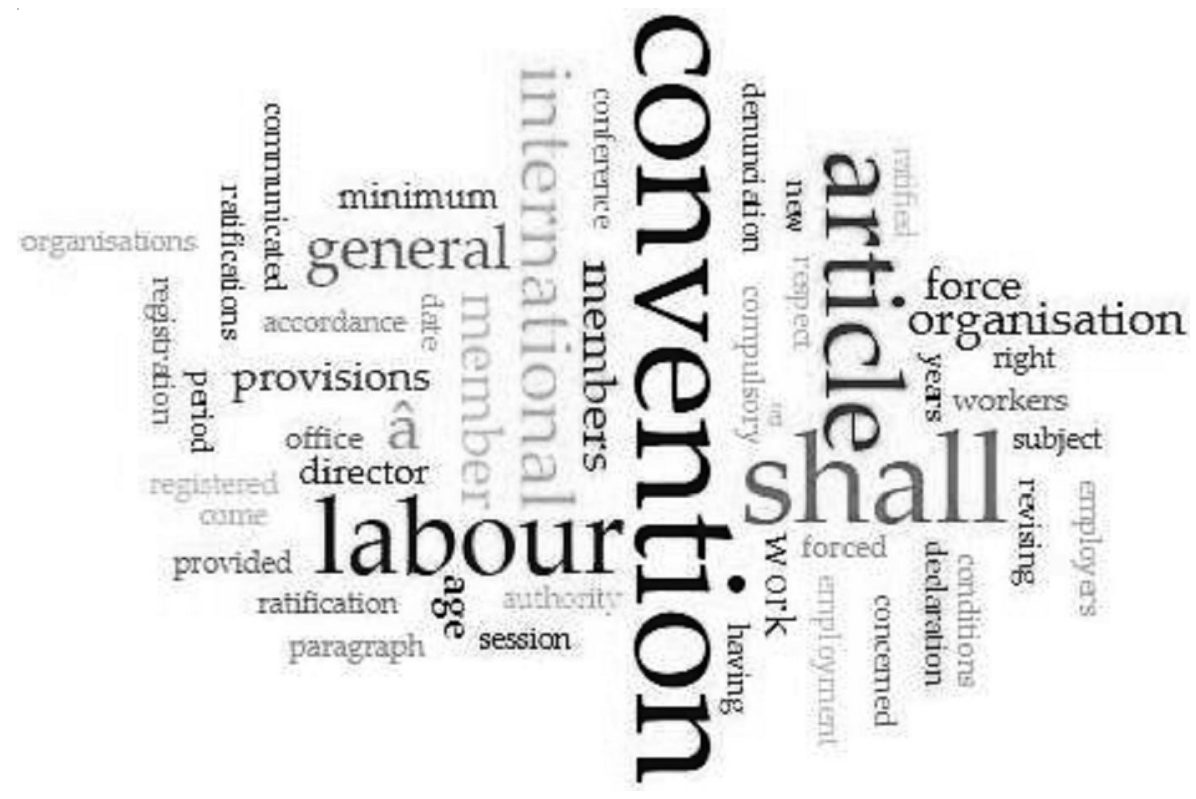

Рис. 1. Статистический анализ корпуса текстов конвенций (облако слов) (более часто встречающиеся слова представлены более крупным шрифтом)

\begin{tabular}{l|l|l|l|ll} 
& $\#$ & Term & Count & Relative \\
\hline$\square$ & 1 & convention & 337 & 23,068 \\
\hline$\square$ & 1 & shall & 261 & 17,866 \\
\hline$\square$ & 1 & article & 224 & 15,333 \\
\hline$\square$ & 1 & labour & 194 & 13,279 \\
\hline$\square$ & 1 & international & 132 & 9,036 \\
\hline$\square$ & 1 & â & 100 & 6,845 \\
\hline$\square$ & 1 & general & 97 & 6,640 \\
\hline$\square$ & 1 & member & 83 & 5,681
\end{tabular}

Рис. 2. Статистический анализ корпуса текстов конвенций

Фактический материал исследования (лемматизированный корпус слов) позволил выделить два типа биграмм - контактные и дистантные. Контактные биграммы - это пары слов, состоящие из главных частей речи, расположенных последовательно друг за другом (например, General Conference, provide guarantees, voluntary negotiation). Дистан- тные биграммы - это неоднородная группа пар слов, представленная несколькими моделями: «главная + главная части речи», «служебная+ главная части речи», но между ними возможно использование еще одной служебной части речи, чаще всего артикля (cause the dismissal, upon the adoption) или предлога (acts of discrimination), либо глав- 
ной части речи, например прилагательного (enjoy adequate protection, outside working hours). При составлении статистических таблиц моделей биграмм и базы данных дистантные биграммы зафиксированы с разделением на две контактные (например: enjoy protection, adequate protection).

Анализ фактического материала дал следующие результаты.

1. Изученные тексты конвенций МОТ содержат большое количество биграмм-коллокаций нескольких типов (см. табл. 1-3):

2. На примере текста Конвенции МОТ «О применении принципов права на организацию и на ведение коллективных переговоров» (конвенция С-098) выявлены наиболее частотные биграммы-коллокации (см. рис. 3, табл. 4), которые представлены следующими моделями:

a) «прилагательное + существительное»: International Convention, International Organisation, International Office, Universal Declaration, Supplementary Convention, General Conference, necessary measure, compulsory labour, formal ratification, complete abolition, political coercion, economic development, racial discrimination, social discrimination, national discrimination, religious discrimination, immediate denunciation, social system, economic system;

б) «глагол + существительное»: constitute violation, prevent labour, register ratification, terminate employment, take effect, express view, suppress labour;

в) «существительное + существительное» - в таких биграммах первый компонент выступает в функции определения, на русский язык они переводятся несколькими способами:

- конструкцией с прилагательным: Labour Convention - Трудовая конвенция;

- конструкцией с существительным в одном из косвенных падежей без предлога: Labour Organisation - организащия труда;

- конструкцией с существительным в одном из косвенных падежей с предлогом: Slavery Convention - Конвенция о рабстве;

г) «существительное + глагол» - подобные биграммы представлены словосочетаниями существительного с модальным или другими глаголами: member undertake, Convention shall, member may, denunciation shall, member will, Conference should, Director shall, Conference convene, Convention provide;

Типы биграмм

\begin{tabular}{|l|l|}
\hline \multicolumn{1}{|c|}{ Контактные биграммы } & \multicolumn{1}{c|}{ Дистантные биграммы } \\
\hline главная + главная части речи & главная + (артикль $)+$ главная части речи \\
главная + служебная части речи & главная + (прилагательное $)+$ главная части речи \\
служебная + главная части речи & предлог $+($ артикль $)+$ главная части речи \\
& предлог $+($ (лавная часть речи $)+$ предлог \\
\hline
\end{tabular}

Таблийа 2

Контактные биграммы

\begin{tabular}{|l|l|l|}
\hline \multicolumn{1}{|c|}{ Главная + главная } & \multicolumn{1}{|c|}{ Главная + служебная } & \multicolumn{1}{|c|}{ Служебная + главная } \\
\hline Governing Body (прил + сущ) & Decide upon (гл + предл) & In respect (предл + сущ) \\
Bargain collectively (гл + нареч) & Together with (нареч + предл) & By reason (предл + сущ) \\
Adopt convention (гл + сущ) & Protection against (сущ + предл) & In virtue (предл + сущ) \\
Anti-union discrimination (композит + сущ) & Participation in (сущ + предл) & In accordance (предл + сущ) \\
Collective bargaining (прил + герундий) & & For registration (предл + сущ) \\
\hline
\end{tabular}

Дистантные биграммы

Таблица 3

\begin{tabular}{|c|c|c|c|}
\hline $\begin{array}{c}\text { Главная + артикль + } \\
\text { главная } \\
\end{array}$ & Главная + прил + главная & $\begin{array}{c}\text { Предл + артикль }+ \\
\text { главная }\end{array}$ & $\begin{array}{c}\text { Предл + главная + } \\
\text { предл }\end{array}$ \\
\hline $\begin{array}{l}\text { Take (the) form } \\
\text { Join }(a) \text { union } \\
\text { Prejudice }(a) \text { worker } \\
\text { Render }(\text { the }) \text { service } \\
\text { Violate }(\text { the }) \text { right }\end{array}$ & $\begin{array}{l}\text { Enjoy (adequate) protection } \\
\text { Adopt (certain) proposals } \\
\text { Compulsory (military) service } \\
\text { Normal (civic) obligations } \\
\text { Exercise (administrative) functions }\end{array}$ & $\begin{array}{l}\text { Upon (the) adoption } \\
\text { With (the) consent } \\
\text { Under (the) control } \\
\text { At (the) expiration } \\
\text { For (the) benefit }\end{array}$ & $\begin{array}{l}\text { By virtue (of) } \\
\text { By means (of) } \\
\text { In respect (of) } \\
\text { With regard (to) } \\
\text { On behalf }(\text { of) }\end{array}$ \\
\hline
\end{tabular}


д) «глагол + глагол» - биграммы с модальным глаголом: shall be, shall come, may denounce, shall notify, shall draw, shall communicate, shall involve, shall remain.

Менее частотными являются биграммы моделей «глагол + наречие», «существительное + прилагательное», «глагол + прилагательное»: oppose ideologically, adopt duly, Director-General, Secretary-General, be binding, be authoritative.

Нетипичны модели «прилагательное + прилагательное», «наречие + наречие», «числительное + числительное», «местоименное наречие + местоименное наречие», а также биграммы, состоящие из двух служебных частей речи.

Текст Конвенции содержит 988 слов, 448 биграмм-коллокаций. В таблице 4 представлены частоты словопар типа «существительное + существительное», «глагол + существительное», «предлог + существительное» и т. д. Частота выражена в среднем количестве пары на 1000 слов текста. Вертикаль от- ражает часть речи первого слова биграммы, горизонталь - второго.

3. Выявлены специфические, тематически обусловленные биграммы: complete abolition, secure abolition, serfdom abolition, constitute violation, rights violation, take measure, effective measure, take effect, suppress (forced) labour.

4. На основе обнаруженной частотности биграмм определена системность их использования. Так, наблюдается последовательное употребление наиболее частотных биграмм: Director-General $\rightarrow$ shall notify, Director-General $\rightarrow$ shall draw, DirectorGeneral $\rightarrow$ shall communicate; abolition of $\rightarrow$ forced labour, abolition of $\rightarrow$ compulsory labour, abolition $\rightarrow$ slave trade, secure abolition $\rightarrow$ complete abolition, shall come $\rightarrow$ into force. Полагаем, что их неоднократное последовательное использование демонстрирует существование лексико-семантической и синтаксической связи между биграммами, что

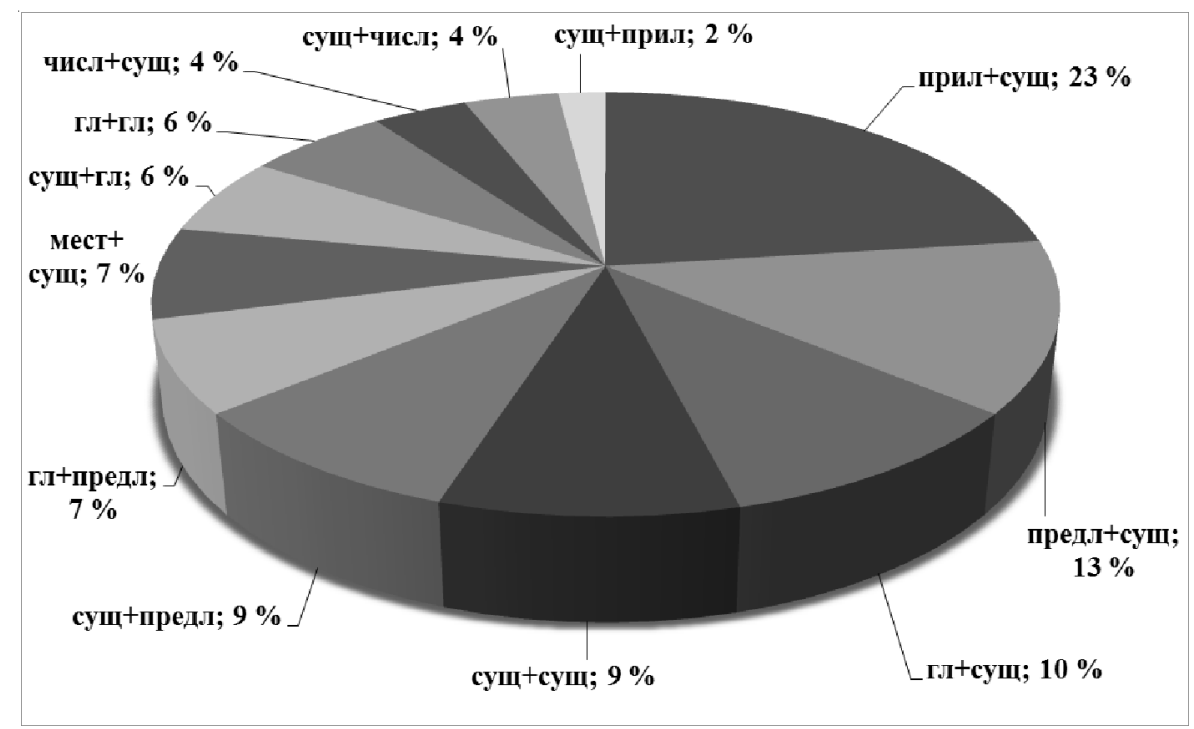

Рис. 3. Частотные биграммы-коллокации

Биграммы частей речи

\begin{tabular}{|l|c|c|c|c|c|c|c|c|}
\hline & Сущ & Глаг & Предл & Союз & Прил & Нареч & Мест & Числ \\
\hline Сущ & 38 & 25 & 38 & 0 & 8 & 0 & 0 & 15 \\
\hline Глаг & 40 & 25 & 30 & 5 & 5 & 3 & 0 & 0 \\
\hline Предл & 54 & 0 & 0 & 0 & 2 & 0 & 3 & 1 \\
\hline Союз & 0 & 0 & 0 & 0 & 0 & 0 & 0 & 0 \\
\hline Прил & 96 & 0 & 5 & 0 & 0 & 0 & 0 & 0 \\
\hline Нареч & 1 & 0 & 1 & 0 & 1 & 0 & 0 & 0 \\
\hline Мест & 29 & 3 & 0 & 0 & 0 & 0 & 0 & 1 \\
\hline Числ & 17 & 0 & 0 & 0 & 0 & 0 & 0 & 2 \\
\hline
\end{tabular}


O.M. Литвишко. Структурные особенности биграмм-коллокаций в международных юридических документах

может рассматриваться как признак системности отношений между ними.

5. С помощью программы Microsoft Access составлена база данных лексико-семантических биграмм-коллокаций, содержащая 200 биграмм (см. рис. 4-6). Она включает следующие разделы: биграмма, перевод, части речи, сфера использования, пример использования.

\section{Выводы}

Результаты анализа позволили сформулировать следующие выводы:

- в текстах конвенций МОТ доминируют двухкомпонентные лексико-семантические единицы, рассматриваемые нами в качестве устойчивых лексико-семантических сочетаний, то есть биграмм-коллокаций;

- степень лексической однородности биграмм-коллокаций соотносится с тематической однородностью проанализированных текстов;

- возможно выделение общих для всех текстов корпуса тематически обусловленных биграмм-коллокаций;

- выделенные биграммы-коллокации в соответствии со структурными характеристиками представлены несколькими моделями.

Результаты исследования могут быть использованы в программах автоматического распознавания и генерирования текстов юридической тематики:

\begin{tabular}{|c|c|c|}
\hline Код - & Биграмма & Части речи \\
\hline 1 & Accept obligation & глагол+существительное \\
\hline 2 & Access to & глагол+предлог \\
\hline 3 & Additional emolument & прилагательное+существительное \\
\hline 4 & Address declaration & глагол+существительное \\
\hline 5 & Adequate instruction & прилагательное+существительное \\
\hline 6 & Administrative authority & прилагательное+существительное \\
\hline 7 & Administrative instruction & прилагательное+существительное \\
\hline 8 & Admission to & существительное+предлог \\
\hline 9 & Adopt convention & глагол+существительное \\
\hline 10 & Affect law & глагол+существительное \\
\hline 11 & Affiliate with & глагол+предлог \\
\hline 12 & After consultation & предлог+существительное \\
\hline 13 & After expiration & предлог+существительное \\
\hline 14 & Allow work & глагол+глагол \\
\hline 15 & Append declaration & глагол+существительное \\
\hline
\end{tabular}

Рис. 4. Фрагмент (1) базы данных биграмм-коллокаций

\begin{tabular}{l|l}
\multicolumn{1}{c}{ Перевод } & \multicolumn{1}{c}{ Сфера использования } \\
\hline принять на себя обязательство & Business, Diplomacy, Insurance, Economy \\
\hline доступ к & General English (GE), Law \\
\hline дополнительный доход & Accounting, Business, Labour Law \\
\hline направить декларацию & International Law, Labour Law \\
\hline соответствующая инструкция & Business, Education, International Law, Labour Law \\
\hline административная власть, орган & Business, Economy, Education, Electronics, Law, Management, Politics \\
\hline административная инструкция & Law, Military, Telecommunications \\
\hline допуск, доступ к & GE, Law \\
\hline утвердить, принять конвенцию & Diplomacy, International Law, International Relations, Politics \\
\hline повлиять на закон & Civil Law, Criminal Law, International Law \\
\hline присоединяться к & Aviation, Business, Law, PR, Politics, Production, Telecommunications \\
\hline после консультирования & GE, Law \\
\hline после истечения срока действия & GE, Law \\
\hline разрешать работать & GE, Law \\
\hline приобщать, прилагать декларацию & Business, International Law, Labour Law
\end{tabular}

Рис. 5. Фрагмент (2) базы данных биграмм-коллокаций 
The employer has to accept obligations arising from the contract of employment

They have access to all facilities in the gym.

The value of the additional emoluments of forage and subsistence would amount at the rate of thirty six dollars per month

Furthermore, a State that made a unilateral declaration took into consideration the reactions of those to whom it was addressed

Regulation 39 sets out the general duties for the provision of information, training and adequate instruction to workers

Agency is an independent administrative authority that participates in running specific parts of an economy or society

The project supported a working group meeting to discuss shortcomings of the existing Administrative Instruction

Your file will be presented at the next monthly admission to membership review for approval

The government has been urged to adopt Domestic Workers' Convention

Amendments to the Constitution may affect the existing law

The Society is not affiliated with any political party

President will announce the date of the upcoming parliamentary polls after consultation with the Election Commission

Some HP inkjet printers include a keeper mechanism that stops you from using their cartridges after an expiration date passes

National traditions do not allow them to work or do business far from home

Some comments are appended to the decraration

Рис. 6. Фрагмент (3) базы данных биграмм-коллокаций

- в лингвистическом мониторинге функционирования языка - выявлении общих особенностей реализации языковой системы в конкретном типе дискурса (юридическом), анализе феноменов естественного языка: типов языковых ошибок, иностранных заимствований, новых слов и значений, тематического распределения лексики;

- в компьютерном моделировании языка и речи - в программах с применением алгоритмов, основанных на данных о частоте употребления лексико-семантических единиц, в программах автоматического распознавания письменного текста и речи, в системах автоматического аннотирования и реферирования;

- при дешифровке кодированного текста, для которой необходимы данные о частоте употребления графем, морфем и лексических единиц, их взаимном расположении и сочетаемости.

Биграммные модели могут быть использованы в целях автоматической обработки текстов юридической тематики (например, трудовых договоров, исковых заявлений по поводу нарушения трудового законодательства): опираясь на биграммные модели текстов, можно улучшать алгоритмы исправления опечаток или автокоррекции вводимого текста.

Предлагаемое исследование может стать основой для дальнейшей разработки классификаций биграмм-коллокаций по типу семантической связи между их элементами. Структурно-семантический анализ выделенных биграмм-коллокаций поможет выявить специфические терминологические единицы (неоднословные термины), широко используемые в текстах конвенций МОТ.

Проанализированная система биграммколлокаций и созданный на ее основе интеллектуальный продукт «База данных англоязычных биграмм-коллокаций сферы международного права (на материале конвенций Международной организации труда)» может получить применение в преподавании юридического английского языка, а также послужить основой разработки автоматизированных обучающих лингвистических систем в сфере профессиональной юридической лексики.

\section{СПИСОК ЛИТЕРАТУРЫ}

Ахманова О. А., 2007. Словарь лингвистических терминов. Изд. 4-е, стер. М. : КомКнига. 576 с.

Баранов А. Н., 2007. Лингвистическая экспертиза текста: теоретические основания и практика. М. : Флинта : Наука. 592 с.

Голев Н. Д., 2000. Юридизация естественного языка как юрислингвистическая проблема // Юрислингвистика- 2 : Русский язык в его естественном и юридическом бытии : межвуз. сб. науч. тр. / отв. ред. Н. Д. Голев. Барнаул : Изд-во Алт. ун-та. С. 9-45.

Голев Н. Д., 2006. Правовая коммуникация в зеркале естественного языка // Юрислингвистика-7 : Русский язык как феномен правовой коммуникации : межвуз. сб. науч. тр. / отв. ред. Н. Д. Голев. Барнаул : Изд-во Алт. ун-та. С. 8-38.

Голев Н. Д., Головачева О. В., 2005. Юрислингвистический словарь инвективной лексики 
русского языка // Юрислингвистика-6 : Инвективное и манипулятивное функционирование языка коммуникации : межвуз. сб. науч. тр. / отв. ред. Н. Д. Голев. Барнаул : Изд-во Алт. ун-та. С. 123-130.

Имплицитность в языке и речи, 1999 / отв. ред. Е. Г. Борисова, Ю. С. Мартемьянов М. : Языки русской культуры. 200 с.

Иорданская Л. Н., Мельчук И. А., 2007. Смысл и сочетаемость в словаре. М. : Языки славянской культуры. 672 с.

Кузнецов А. М., Бурдин Л. С., Солнцева Н. В., 2006. Юрислингвистика: Язык и право : Научноаналитический обзор. М. : ИНИОН. 69 с.

Хохлова М. В., 2008. Экспериментальная проверка методов выделения коллокаций // Slavica Helsingiensia 34. Инструментарий русистики : Корпусные подходы / под ред. А. Мустайоки, М. В. Копотева, Л. А. Бирюлина, Е. Ю. Протасовой. Helsinki : Helsingin yliopisto. T. 34. C. 343-357.

Юрислингвистика. URL: http://journal.asu.ru/ index.php/urisl (дата обращения: 12.04.2018).

Ягунова Е. В., Пивоварова Л. М., 2010а. Извлечение и классификация коллокаций на материале научных текстов. Предварительные наблюдения // Прикладная лингвистика в науке и образовании : материалы V Междунар. науч.практ. конф. памяти Р.Г. Пиотровского (2526 марта 2010 г., г. Санкт-Петербург). СПб. : Лема. С. 356-364.

Ягунова Е. В., Пивоварова Л. М., 2010б. Природа коллокаций в русском языке. Опыт автоматического извлечения и классификации на материале новостных текстов // Научно-техническая информация. Серия 2, Информационные процессы и системы. № 6. С. 30-40.

Язык закона, 1990 / под ред. А. С. Пиголкина. М. : Юрид. лит. 192 с.

Callanan H., Edwards L., 2010. Absolute Legal English. London : Delta Publishing. 112 p.

Collins M., 1996. A New Statistical Parser Based on Bigram Lexical Dependencies // Proceedings of the $34^{\text {th }}$ Annual Meeting of the ACL. Santa Cruz, California. P. 184-191. DOI: 10.3115/ 981863.981888.

Coulthard M., 1994. Advances in Written Text Analysis. New York : Routledge. $336 \mathrm{p}$.

Coulthard M., Johnson A., Wright D., 2016. An Introduction to Forensic Linguistics: Language in Evidence. $2^{\text {nd }}$ ed. New York : Routledge. 271 p.

EckardtB., 2000. Fachsprache als Kommunikationsbarrire? Verständigungsprobleme zwischen Juristen und Laien. Wiesbaden : Dt. Univ.Verl. 157 S.

Evert S., 2005. The Statistics of Word Cooccurrences: Word Pairs and Collocations. Ph. D. thesis, University of Stuttgart. $353 \mathrm{p}$.
Haigh R., 2015. Legal English. New York: Routledge. 360p. Hermes - Journal of linguistics. URL: http:// hermes.asb.dk (date of access: 14 April 2018).

Khokhlova M., Zakharov V., 2009. Statistical Collocability of Russian Verbs // After Half a Century of Slavonic Natural Language Processing / ed. by Dana Hlavačkova, Aleš Horak, Klara Osolsobě, Pavel Rychly. Brno : Masaryk University Press. P. 105-112.

Krois-Lindner A., 2011. International Legal English. Cambridge : Cambridge University Press. 337 p.

Language in the Legal Process, 2002 / ed. by J. Cotterill. New York : Palgrave Macmillan. 276 p.

LSP and professional communication. URL: https:/ /rauli.cbs.dk/index.php/lsp (date of access:10.04.2018).

Stygall G., 2007. Review of The Lynching of Language: Gender, Politics, and Power in the Hill-Thomas Hearings by Sandra L. Ragan [et al.] // International Journal of Speech Language and the Law. № 7. P. $128-130$.

The International Journal of Speech, Language and the Law. URL: http://www.iafl.org/journal.php (date of access: 10.04.2018).

\section{ИСТОЧНИК}

Labour Standards // International Labour Organization. URL: http://www.ilo.org/global/standards/lang-en/index.htm.

\section{REFERENCES}

Akhmanova O.A., 2007. Slovar lingvisticheskikh terminov [Dictionary of Linguistic Terms]. Moscow, KomKniga Publ. 576 p.

Baranov A.N., 2007. Lingvisticheskaya ekspertiza teksta: teoreticheskie osnovaniya i praktika [Linguistic Expertise of the Text: Theoretical Foundations and Practice]. Moscow, Flinta Publ.; Nauka Publ. 592 p.

Golev N.D., 2000. Yuridizatsiya estestvennogo yazyka kak yurislingvisticheskaya problema [Juridification of Natural Language as a Legal-Linguistic Problem]. Yurislingvistika-2: Russkiy yazyk $v$ ego estestvennom i yuridicheskom bytii: mezhvuz. sb. nauch. tr. [Juridical Linguistics-2. Russian in Its Natural and Legal Being. Interuniversity Collection of Scientific Works]. Barnaul, Izd-vo Altayskogo universiteta, pp. 9-45.

Golev N.D., 2006. Pravovaya kommunikatsiya v zerkale estestvennogo yazyka [Legal Communication in the Mirror of Natural Language]. Yurislingvistika-7: Russkiy yazyk kak fenomen pravovoy 
kommunikatsii : mezhvuz. sb. nauch. tr. [Juridical Linguistics-7. Russian as the Phenomenon of Legal Communication. Interuniversity Collection of Scientific Works]. Barnaul, Izd-vo Altayskogo universiteta, pp. 8-38.

Golev N.D., Golovacheva O.V., 2005. Yurislingvisticheskiy slovar invektivnoy leksiki russkogo yazyka [Legal Linguistic Dictionary of Invective Vocabulary of the Russian Language]. Yurislingvistika-6: Invektivnoe $i$ manipulyativnoe funktsionirovanie yazyka kommunikatsii: mezhvuz. sb. nauch. tr. [Juridical Linguistics-6. Invective and Manipulative Functioning of the Language]. Barnaul, Izd-vo Altayskogo universiteta, pp.123-130.

Borisova E.G., Martemyanov Yu.S., eds., 1999. Implitsitnost $v$ yazyke $i$ rechi [Implicitness in the Language and Speech]. Moscow, Yazyki russkoy kultury Publ. 200 p.

Iordanskaya L.N., Melchuk I.A., 2007. Smysl $i$ sochetaemost $v$ slovare [Meaning and Compatibility in a Dictionary]. Moscow, Yazyki slavyanskoy kultury Publ. $672 \mathrm{p}$.

Kuznetsov A.M., Burdin L.S., Solntseva N.V., 2006. Yurislingvistika: Yazyk i pravo : Nauchnoanaliticheskiy obzor [Legal Linguistics: Language and Law: Scientific-Analytical Review]. Moscow, INION. 69 p.

Khokhlova M.V., 2008. Eksperimentalnaya proverka metodov vydeleniya kollokatsiy [Experimental Testing of Methods of Highlighting Collocations]. Slavica Helsingiensia 34. Instrumentariy rusistiki: Korpusnye podkhody [Slavica Helsingiensia 34. Tools of Russian Studies: Corpus Approaches]. Helsinki, Helsingin yliopisto, pp. 343-357.

Yurislingvistika [Legal Linguistics]. URL: http:// journal.asu.ru/index.php/urisl (accessed 12 April 2018).

Yagunova E.V., Pivovarova L.M., 2010a. Izvlechenie i klassifikatsiya kollokatsiy na materiale nauchnykh tekstov. Predvaritelnye nablyudeniya [Extraction and Classification of Collocations on the Material of Scientific Texts. Preliminary Observations]. Prikladnaya lingvistika $v$ nauke $i$ obrazovanii. materialy V Mezhdunar. nauch.-prakt. konf. pamyati R.G. Piotrovskogo (25-26 marta 2010 g. [Applied Linguistics in Science and Education. Proceedings of the $5^{\text {th }}$ International Scientific and Practical Conference in Memory of R.G. Piotrovsky (25-26 March 2010, Saint Petersburg)]. Saint Petersburg, Lema Publ., pp. 356-364.

Yagunova E.V., Pivovarova L.M., 2010b. Priroda kollokatsiy v russkom yazyke. Opyt avtomaticheskogo izvlecheniya i klassifikatsii na materiale novostnykh tekstov [The Nature of Collocations in Russian. Experience of Automatic
Extraction and Classification on the Material of News Texts]. Nauchno-tekhnicheskaya informatsiya. Series 2, Informatsionnye protsessy i sistemy [Automatic Documentation and Mathematical Linguistics], no. 6, pp. 30-40.

Yazyk zakona, 1990 [The Language of Law]. Moscow, Yuridicheskaya literatura Publ. 192 p.

Callanan H., Edwards L., 2010. Absolute Legal English. London, Delta Publishing. $112 \mathrm{p}$.

Collins M., 1996. A New Statistical Parser Based on Bigram Lexical Dependencies. Proceedings of the $34^{\text {th }}$ Annual Meeting of the ACL, pp. 184191. DOI:10.3115/981863.981888.

Coulthard M., 1994. Advances in Written Text Analysis. New York, Routledge. 336 p.

Coulthard M., Johnson A., Wright D., 2016. An Introduction to Forensic Linguistics: Language in Evidence, $2^{\text {nd }}$ ed. New York, Routledge. 271 p.

EckardtB., 2000. Fachspracheals Kommunikationsbarrire? Verständigungsprobleme zwischen Juristen und Laien. Wiesbaden, Dt. Univ. Verl. 157 S.

Evert S., 2005. The Statistics of Word Cooccurrences: Word Pairs and Collocations. $\mathrm{Ph}$. D. thesis, University of Stuttgart. $353 \mathrm{p}$.

Haigh R., 2015. Legal English. New York, Routledge. 360 p.

Hermes - Journal of Linguistics. URL: http:// hermes.asb.dk (accessed 14 April 2018).

Khokhlova M., Zakharov V., 2009. Statistical Collocability of Russian Verbs. Hlavačkova D., Horak A., Osolsobě K., Rychly P., eds. After Half a Century of Slavonic Natural Language Processing. Brno, Masaryk University Press, pp. 105-112.

Krois-Lindner A., 2011. International Legal English. Cambridge University Press. 337 p.

Cotterill J., ed., 2002. Language in the Legal Process. New York, Palgrave Macmillan. 276 p.

LSP and Professional Communication. URL: https://rauli.cbs.dk/index.php/lsp (accessed 10 April 2018)

Stygall G., 2007. Review of The Lynching of Language: Gender, Politics, and Power in the Hill-Thomas Hearings by Sandra L. Ragan et al. International Journal of Speech Language and the Law, no. 7, pp. 128-130.

The International Journal of Speech, Language and the Law. URL: http://www.iafl.org/journal.php (accessed 10 April 2018).

\section{SOURCE}

Labour Standards. International Labour Organization. URL: http://www.ilo.org/global/ standards/lang--en/index.htm. 
О.М. Литвишко. Структурные особенности биграмм-коллокаций в международных юридических документах

\section{Information about the Author}

Ol'ga M. Litvishko, Candidate of Sciences (Politics), Associate Professor, Department of English and Professional Communication, Pyatigorsk State University, Prosp. Kirova, 63, 357500 Pyatigorsk, Russia, litvishko@pgu.ru, https://orcid.org/0000-0001-8430-8501

\section{Информация об авторе}

Ольга Михайловна Литвишко, кандидат политических наук, доцент кафедры английского языка и профессиональной коммуникации, Пятигорский государственный университет, просп. Кирова, 63, 357500 г. Пятигорск, Россия, litvishko@pgu.ru, https://orcid.org/0000-0001-8430-8501 